MATEC Web of Conferences 33, 05002 (2015)

DOI: $10.1051 /$ matecconf/ 20153305002

(C) Owned by the authors, published by EDP Sciences, 2015

\title{
First Principles and Monte Carlo Calculations of Structural and Magnetic Properties of $\mathrm{Fe}_{x} \mathrm{Ni}_{2-x} \mathrm{Mn}_{1+y} \mathrm{Al}_{1-y}$ Heusler Alloys
}

\author{
Mikhail Zagrebin ${ }^{1,2, a}$, Vladimir Sokolovskiy ${ }^{1,3}$, Marina Klyuchnikova ${ }^{1}$ and Vasiliy Buchelnikov ${ }^{1}$ \\ ${ }^{1}$ Chelyabinsk State University, Condensed Matter Physics Department, 454001 Chelyabinsk, Russia \\ ${ }^{2}$ National Research South Ural State University, Mathematical Physics Equations Department, 454080 Chelyabinsk, Russia \\ ${ }^{3}$ National University of Science and Technology "MIS\&S", Moscow, 119049, Russia
}

\begin{abstract}
The composition dependences of crystal lattice parameters, bulk moduli, magnetic moments, magnetic exchange parameters, and Curie temperatures in $\mathrm{Fe}_{x} \mathrm{Ni}_{2-x} \mathrm{Mn}_{1+y} \mathrm{Al}_{1-y}(0.2 \leq x \leq 1.8 ; 0.0 \leq y \leq 0.6)$ Heusler alloys are investigated with the help of first principles and Monte Carlo calculations. It is shown that equilibrium lattice parameters and $\mathrm{Mn}_{\mathrm{Y}}-\mathrm{Mn}_{\mathrm{Z}}$ magnetic exchange interactions increase with increasing Fe content $(x)$. A crossover from ferromagnetic to antiferromagnetic interaction between nearest neighbors $\mathrm{Mn}_{Y}$ and $\mathrm{Mn}_{Z}$ atoms was observed in compositions with $x \geq 1.4$ and $0.2 \leq y \leq 0.6$. Such magnetic competitive behavior points to a complex magnetic structure in $\mathrm{Fe}_{x} \mathrm{Ni}_{2-x} \mathrm{Mn}_{1+y} \mathrm{Al}_{1-y}$. Calculated values of lattice parameters, magnetic moments, and Curie temperatures are in a good agreement with other theoretical results and available experimental data.
\end{abstract}

\section{Introduction}

Nowadays, Heusler alloys have attracted a huge interest because of various effects (such as the shape memory, magnetocaloric effect (MCE), exchange bias, and superelasticity) and their potential applications as intelligent functional materials [1-3]. In recent years, novel $\mathrm{Fe}_{2+x} \mathrm{Mn}_{1-x} \mathrm{Al}$ Heusler compounds have been intensively investigated by experimentalists and theoreticians [4-6]. These magnetic materials are considered to be very promising for technological applications utilizing their properties such as anomalous behaviours of optical, magnetic and transport properties.

One of the ways to enhance the magnetic and structural properties of Fe-Mn-Al system is related to addition of fourth $3 d$ element. Recent experiments have shown that the substitution of $7.5 \%$ of $\mathrm{Fe}$ for $\mathrm{Ni}$ in the $\mathrm{Fe}_{51} \mathrm{Mn}_{34} \mathrm{Al}_{15}$ results in an enhancement of the superelastic behavior observed over a wide temperature range from 77 to $513 \mathrm{~K}$ [9-11]. A good room-temperature strength and a significant ductility was found in the $\mathrm{Fe}_{30} \mathrm{Ni}_{20} \mathrm{Mn}_{35} \mathrm{Al}_{15}$ alloy with a higher $\mathrm{Ni}$ content $[7,8]$. Further increase in Ni content leads to increase in MCE. Thus, the positive magnetic entropy change $(\Delta S \approx 3.35 \mathrm{~J} / \mathrm{kgK})$ in $\mathrm{Ni}_{44} \mathrm{Fe}_{6} \mathrm{Mn}_{32} \mathrm{Al}_{18}$ under magnetic field change of $30 \mathrm{kOe}$ has been found by Xuan et al. [12]. Based upon the information, we can suggest that the families of $\mathrm{Fe}_{x} \mathrm{Ni}_{2-x} \mathrm{Mn}_{1+y} \mathrm{Al}_{1-y}$ compositions are the promising candidates in the development of multifunctional materials.

In this work, we present the $a b$ initio and MonteCarlo calculations of structural and magnetic properties

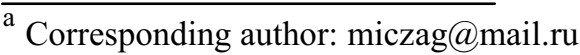

of series of $\quad \mathrm{Fe}_{x} \mathrm{Ni}_{2-x} \mathrm{Mn}_{1+y} \mathrm{Al}_{1-y} \quad(0.2 \leq x \leq 1.8$, $0.0 \leq y \leq 0.6$ ) compounds.

\section{Calculation details}

\subsection{Ab initio calculation details}

All the calculations were performed using the density functional theory as part of the spin-polarized relativistic Korringa-Kohn-Rostoker (SPR-KKR) package [13, 14]. This code is based on the KKR-Green's function formalism that makes possible using of the multiplescattering theory, and the electronic structure is expressed in terms of the corresponding Green's function as opposed to Bloch wave functions and eigenvalues. In this code, a chemical disorder is treated through the coherent potential approximation [14]. The generalized gradient approximation for the exchange correlation functional in the formulation of Perdew, Burke and Ernzerhof was taken into account [16]. The SPR-KKR was used to determine the equilibrium parameter of a cubic L2 structure with ferromagnetic (FM) order. Where, all magnetic moments of $\mathrm{Fe}, \mathrm{Ni}$ and $\mathrm{Mn}$ atoms are parallel [5]. It should be pointed out that the $\mathrm{L} 2{ }_{1}$ cubic structure can be represented as four interpenetrating $f c c$ sublattices with $\mathrm{Al}$ at site $(0,0,0), \mathrm{Mn}$ at site $(1 / 2,1 / 2$, $1 / 2)$ and two Fe at sites $(1 / 4,1 / 4,1 / 4)$ and $(3 / 4,3 / 4,3 / 4)$, respectively. In order to formation of off-stoichiometric Fe-Ni-Mn-Al alloys, the excess of $\mathrm{Ni}$ and $\mathrm{Mn}$ were randomly located at $\mathrm{Fe}$ and $\mathrm{Al}$ sites. Therefore, we use follow designations: $\mathrm{Mn}_{\mathrm{Y}}$ and $\mathrm{Mn}_{\mathrm{Z}}$. Where, $\mathrm{Mn}_{\mathrm{Y}}$ atoms are located at regular $\mathrm{Mn}$ sublattice and $\mathrm{Mn}_{\mathrm{Z}}$ atoms are

This is an Open Access article distributed under the terms of the Creative Commons Attribution License 4.0, which permits unrestricted use distribution, and reproduction in any medium, provided the original work is properly cited Article available at nttp://www.matec-conterences.org or http://dx.doi.org/10.1051/mateccont/20153305002 
occupied the Al sublattice. For the optimized lattice parameter the magnetic exchange coupling parameters $J_{i j}$ were calculated by using the expression proposed by Liechtenstein et al. [15], which is employed in the SPRKKR package.

\subsection{Monte Carlo Hamiltonian}

In order to simulate temperature dependences of the qualitative dependence of the Curie temperature in the austenite, we used the $q$-state Potts Hamiltonian with different $q$ states for the magnetic atoms. As it is well known, the Potts model allows to describe both first and second order phase transitions observed in Heusler alloys in comparison with the Heisenberg model. We would like to mention that critical temperatures obtained by the Potts model are consistent with the results obtained by Heisenberg model. A reader can find the addition information about it in Ref. [17]. Since our goal is related to estimation of the Curie temperature of austenite that we will take into account only a magnetic part of the total Hamitonian with "ab initio" exchange coupling constants.

We note that the information about total Hamiltonian containing magnetic, elastic, and magnetoelastic terms is presented in Ref. [18]. Therefore, the magnetic part of Hamiltonian at zero magnetic field can be written as:

$$
H=-\sum J_{i j} \delta_{s_{i}, s_{j}},
$$

where $J_{i j}$ are exchange coupling constants between magnetic atoms at sites $i$ and $j$, which are taken from $a b$ initio calculations. $S_{i}$ is the magnetic degree of freedom at site $i$ which can take on $q$ integer values depending on the total spin moment $S$ of an atom. The Kronecker symbol $\delta_{s_{i}, s_{j}}$ restricts the spin-spin interactions to the interactions between the same $S_{i}$ states for Fe, Ni and $\mathrm{Mn}$. Threedimensional lattice containing 3925 atoms with periodic boundary conditions was considered. The simulations were carried out by using using the classical Metropolis algorithm [18].

\section{Computational Results}

\subsection{Equilibrium lattice parameter and bulk modulus}

The equilibrium lattice parameter in austenite of $\mathrm{Fe}_{x} \mathrm{Ni}_{2-x} \mathrm{Mn}_{1+y} \mathrm{Al}_{1-y}$ as a function of $\mathrm{Fe}$ excess $(x)$ at different values of Mn excess (y) is presented in Fig. 1. It is seen that lattice constants decrease with increasing $\mathrm{Fe}$ content. It should be noted that our theoretical lattice parameters for $\mathrm{Ni}_{2} \mathrm{MnAl}$ and $\mathrm{Fe}_{2} \mathrm{MnAl}$ are in a good agreement with results obtained from another $a b$ initio calculations $[5,19]$. Obtained equilibrium lattice parameters were used for subsequent calculations of magnetic properties of $\mathrm{Fe}_{x} \mathrm{Ni}_{2-x} \mathrm{Mn}_{1+y} \mathrm{Al}_{1-y}$ alloys.

In Figure 2 we present the contour plot of a bulk modulus for $\mathrm{Fe}_{x} \mathrm{Ni}_{2-x} \mathrm{Mn}_{1+y} \mathrm{Al}_{1-y}$ projected on the plane $(x, y)$. As can be seen the bulk modulus decreases until $x \approx 1.25$ and further decreases with increasing Fe excess. The smallest value of a bulk modulus $(\approx 85 \mathrm{GPa})$ is found for the $\mathrm{Fe}_{0.2} \mathrm{Ni}_{1.8} \mathrm{Mn}_{1.6} \mathrm{Al}_{0.4}$ composition.

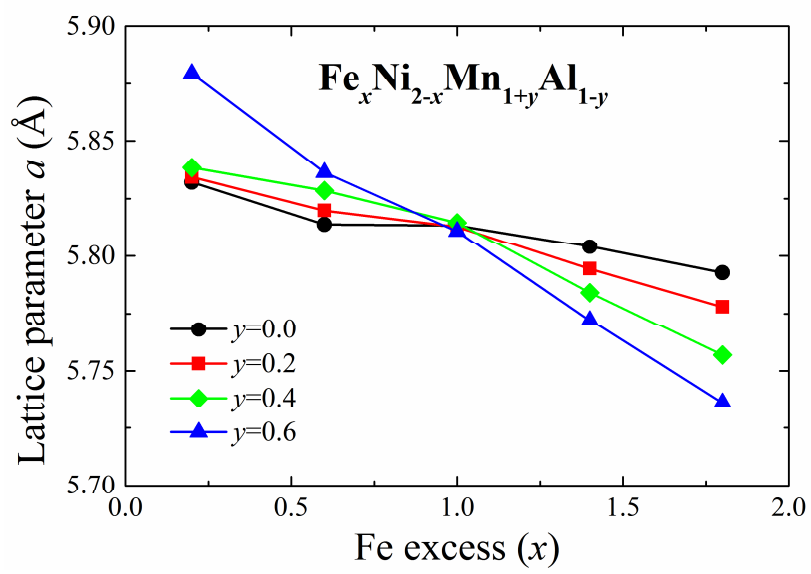

Figure 1. Equilibrium lattice parameter in austenite of $\mathrm{Fe}_{x} \mathrm{Ni}_{2-x} \mathrm{Mn}_{1+y} \mathrm{Al}_{1-y}$ for different value of Mn excess (y) as a function of $\mathrm{Fe}$ excess $(x)$.

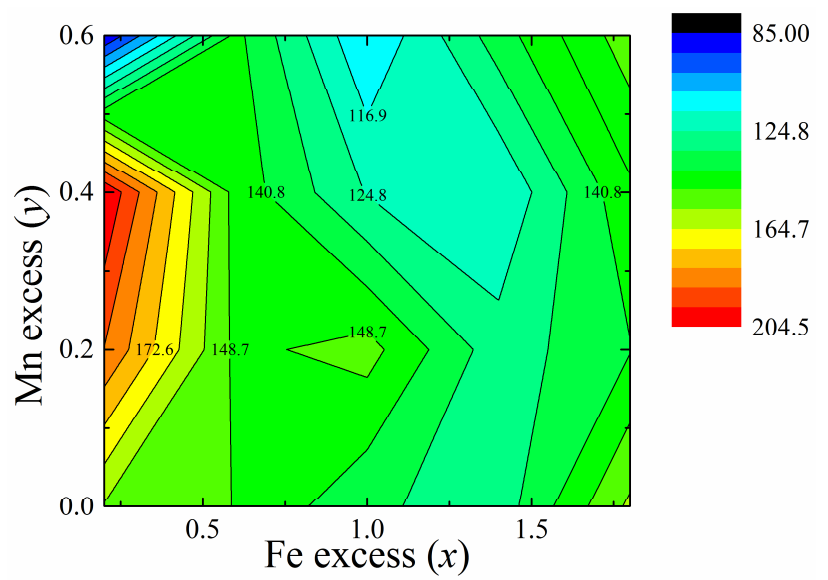

Figure 2. The bulk modulus contour in austenite of $\mathrm{Fe}_{x} \mathrm{Ni}_{2-x} \mathrm{Mn}_{1+y} \mathrm{Al}_{1-y}$ for different value of $\mathrm{Fe}(x)$ and $\mathrm{Mn}$ excesses $(y)$.

\subsection{Spin magnetic moment}

In this subsection we discuss calculation results of partial and total magnetic moments of $\mathrm{Fe}_{x} \mathrm{Ni}_{2-x} \mathrm{Mn}_{1+y} \mathrm{Al}_{1-y}$ alloys. In Fig. 3a we depict the distribution of a total magnetic moment mapped on the plane $(x, y)$. The same distribution of Fe moment shown in Fig. 3b. It can be seen from Figure $3 \mathrm{a}$ that the total magnetic moment increases with increasing $\mathrm{Mn}$ content. The lowest (highest) value of a magnetic moment is closed to 4 (7) $\mu_{B}$ for $\mathrm{Fe}_{0.2} \mathrm{Ni}_{1.8} \mathrm{MnAl}\left(\mathrm{Fe}_{1.0} \mathrm{Ni}_{1.0} \mathrm{Mn}_{1.6} \mathrm{Al}_{0.4}\right)$ composition, respectively. The dependences of partial magnetic moment of $\mathrm{Fe}$ atoms have a complex behavior (Fig. 3b).

\subsection{Magnetic exchange constants}

Figure 4 displays the magnetic exchange parameters in austenitic phase of $\mathrm{Fe}_{0.2} \mathrm{Ni}_{1.8} \mathrm{Mn}_{1.2} \mathrm{Al}_{0.8} \quad$ (Fig. 4a) and $\mathrm{Fe}_{1.8} \mathrm{Ni}_{0.2} \mathrm{Mn}_{1.4} \mathrm{Al}_{0.6}$ (Fig. $4 \mathrm{~b}$ ) as functions of a distance between pairs of atoms. These compositions are closed to experimental compositions $\mathrm{Ni}_{44} \mathrm{Fe}_{6} \mathrm{Mn}_{32} \mathrm{Al}_{18}$ and 
$\mathrm{Fe}_{43.5} \mathrm{Ni}_{7.5} \mathrm{Mn}_{34} \mathrm{Al}_{15}$ showing the promising magnetocaloric and superelastic properties [9-11]. Here and further, the positive exchange constants $\left(J_{i j}>0\right)$ are characterized the FM coupling, whereas the negative ones $\left(J_{i j}<0\right)$ point to the antiferromagnetic (AF) coupling. The oscillating damped behavior of $J_{i j}$ can be observed from Figure 4 . We would like to note that this trend is typical for the RKKY-exchange interaction [20]. In the case of $\mathrm{Fe}_{0.2} \mathrm{Ni}_{1.8} \mathrm{Mn}_{1.2} \mathrm{Al}_{0.8}$, the strongest $\mathrm{FM}$ interaction between nearest-neighbor $(\mathrm{NN}) \mathrm{Fe}-\mathrm{Mn}_{\mathrm{Y}}$ and $\mathrm{Ni}-\mathrm{Mn}_{\mathrm{Y}, \mathrm{Z}}$ atoms can be seen from Fig. 4a. Note, that values of these interactions are approximately closed to $7 \mathrm{meV}$. The AF interaction is observed between $\mathrm{NN} \mathrm{Mn}_{\mathrm{Y}}-\mathrm{Mn}_{\mathrm{Z}}$ atoms in the first coordination sphere. The Fe-Fe interaction is the FM one and it is closed to zero. In regard to the second coordination shell, we can see that this interaction is also closed to zero, but its nature is AF. Contrary to that the $\mathrm{Fe}-\mathrm{Fe}$ interaction within the third coordination sphere splits into two interactions: weak FM and strong $\mathrm{AF}$ $(\approx-5 \mathrm{meV})$ ones. On the other hand, the fourth $\mathrm{NN}$ interaction between $\mathrm{Fe}$ atoms becomes the FM one. This clearly demonstrates the competitive behavior between the $\mathrm{FM}$ and $\mathrm{AF}$ interactions. The $\mathrm{Fe}-\mathrm{Mn}_{\mathrm{Z}}$ interaction is $\mathrm{FM}$ and it equals $2 \mathrm{meV}$.
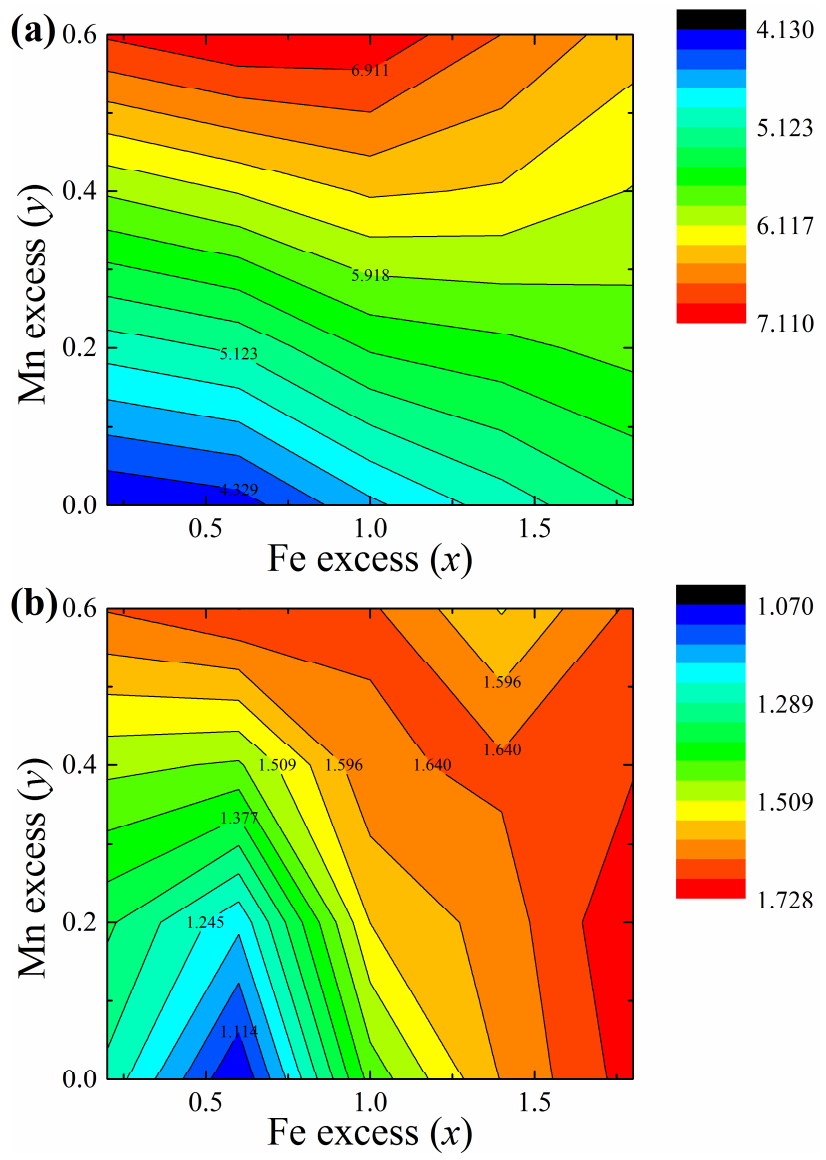

Figure 3. The magnetization contour in austenite of $\mathrm{Fe}_{x} \mathrm{Ni}_{2-x} \mathrm{Mn}_{1+y} \mathrm{Al}_{1-y}$ for different value of $\mathrm{Fe}(x)$ and $\mathrm{Mn}$ excesses (y). a) total magnetization; b) partial magnetization of Fe atoms.
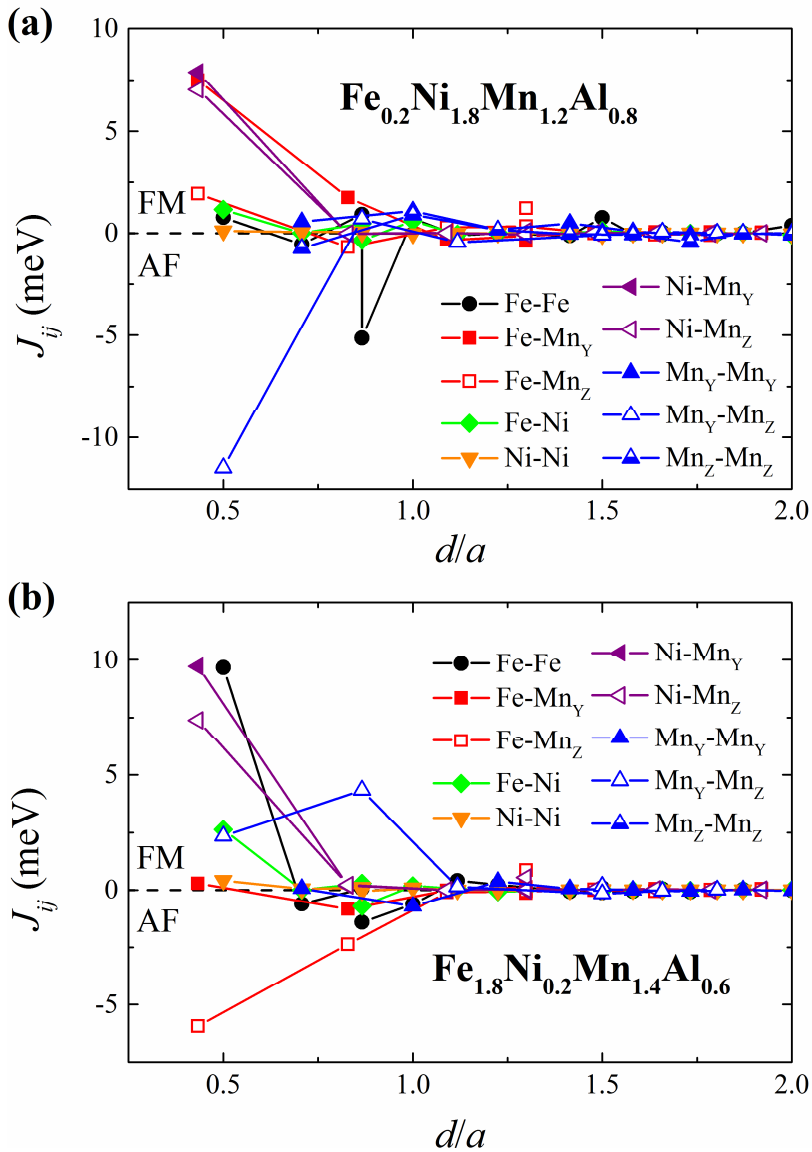

Figure 4. Calculated exchange couplings parameters in austenite of $\mathrm{Fe}_{x} \mathrm{Ni}_{2-x} \mathrm{Mn}_{1+y} \mathrm{Al}_{1-y}$ as a function of a distance between pairs of atoms $i$ and $j$ (in units of the lattice constant $a$ ). a) $\mathrm{Fe}_{0.2} \mathrm{Ni}_{1.8} \mathrm{Mn}_{1.2} \mathrm{Al}_{0.8} ;$ b) $\mathrm{Fe}_{1.8} \mathrm{Ni}_{0.2} \mathrm{Mn}_{1.4} \mathrm{Al}_{0.6}$.

Let us discuss the exchange interactions for the $\mathrm{Fe}_{1.8} \mathrm{Ni}_{0.2} \mathrm{Mn}_{1.4} \mathrm{Al}_{0.6}$ composition. We can see that $\mathrm{Fe}-\mathrm{Fe}$ and $\mathrm{Fe}-\mathrm{Ni}$ interactions increase, while $\mathrm{Fe}-\mathrm{Mn}_{\mathrm{Y}, \mathrm{Z}}$ interactions are found to decrease at the crossover from $\mathrm{Fe}_{0.2} \mathrm{Ni}_{1.8} \mathrm{Mn}_{1.2} \mathrm{Al}_{0.8}$ to $\mathrm{Fe}_{1.8} \mathrm{Ni}_{0.2} \mathrm{Mn}_{1.4} \mathrm{Al}_{0.6}$ alloy. Besides, the $\mathrm{Fe}-\mathrm{Mn}_{\mathrm{Y}}$ exchange goes to zero while the $\mathrm{Fe}-\mathrm{Mn}_{Z}$ $\left(\mathrm{Mn}_{\mathrm{Y}}-\mathrm{Mn}_{\mathrm{Z}}\right)$ ones change their sign from positive (negative) to negative (positive), respectively. A strong competitive behavior between FM and AF interactions clearly shows that these alloys have a complex magnetic structure.

The behaviors of exchange coupling parameters between nearest $\mathrm{Mn}_{\mathrm{Y}}-\mathrm{Mn}_{\mathrm{Z}}$ and $\mathrm{Fe}-\mathrm{Fe}$ atoms in austenite of $\mathrm{Fe}_{x} \mathrm{Ni}_{2-x} \mathrm{Mn}_{1+y} \mathrm{Al}_{1-y}$ as a function of $\mathrm{Fe}$ content $(x)$ are depicted in Figure 5. We can see from Fig. 5a that the Fe$\mathrm{Fe}$ interaction shows a non-linear behavior characterizing by an increase and a decrease in $\mathrm{Fe}=\mathrm{Fe}$ coupling for all compositions with $0.0 \leq y \leq 0.6$. The largest $\mathrm{FM}$ interaction (about $27 \mathrm{meV}$ ) is observed between Fe atoms for composition with $x=0.6$ and $y=0.6$. With respect to the $\mathrm{Mn}_{\mathrm{Y}}-\mathrm{Mn}_{\mathrm{Z}}$ interaction shown in Fig. 5 b, it is seen that the substitution of $\mathrm{Fe}$ for $\mathrm{Ni}$ leads to a linear increase in this interaction. Moreover, the crossover between AF/FM exchange interactions can be observed at compositions with $x=1.5$ and $y \leq 0.4$. Obtained values of magnetic exchange constants were used for further simulations of magnetization curves for $\mathrm{Fe}_{x} \mathrm{Ni}_{2-x} \mathrm{Mn}_{1+y} \mathrm{Al}_{1-y}$ alloys as functions of a temperature by the Monte Carlo method. 
(a)
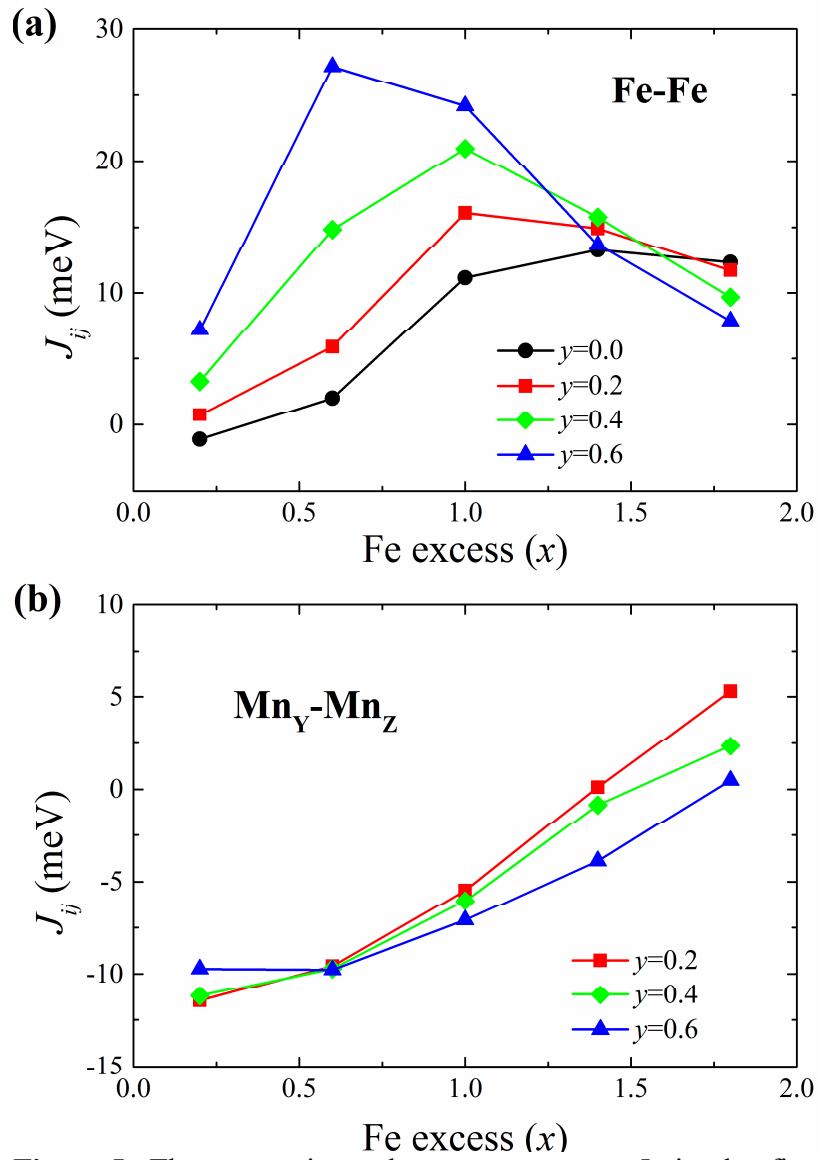

Figure 5. The magnetic exchange parameters $J_{i j}$ in the first coordination sphere in austenite of $\mathrm{Fe}_{x} \mathrm{Ni}_{2-x} \mathrm{Mn}_{1+y} \mathrm{Al}_{1-y}$ as a function of $\mathrm{Fe}$ excess (x). a) $\mathrm{Fe}-\mathrm{Fe}$ coupling; b) $\mathrm{Mn}_{\mathrm{Y}}-\mathrm{Mn}_{\mathrm{Z}}$ coupling.

\subsection{Curie temperature}

The temperature dependences of magnetizations in austenitic phase of $\mathrm{Fe}_{0.2} \mathrm{Ni}_{1.8} \mathrm{Mn}_{1.2} \mathrm{Al}_{0.8}$ and $\mathrm{Fe}_{1.8} \mathrm{Ni}_{0.2} \mathrm{Mn}_{1.4} \mathrm{Al}_{0.6}$ under zero magnetic field are shown in Figure 6.

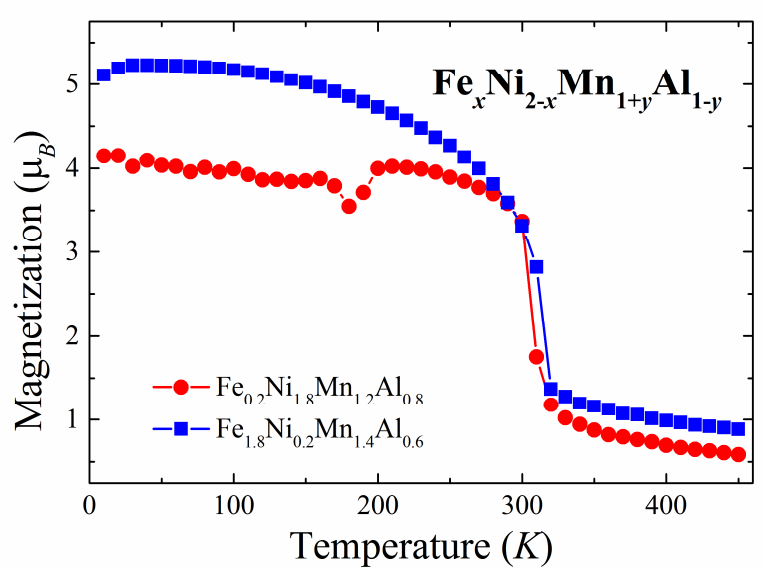

Figure 6. Magnetization $M$ in austenite of $\mathrm{Fe}_{x} \mathrm{Ni}_{2-x} \mathrm{Mn}_{1+y} \mathrm{Al}_{1-y}$ as a function of temperature $T$.

We can see that the Curie temperatures of austenite are 307 and $316 \mathrm{~K}$ for $\mathrm{Fe}_{0.2} \mathrm{Ni}_{1.8} \mathrm{Mn}_{1.2} \mathrm{Al}_{0.8}$ and $\mathrm{Fe}_{1.8} \mathrm{Ni}_{0.2} \mathrm{Mn}_{1.4} \mathrm{Al}_{0.6}$ alloys, respectively. These values are in a good agreement with experimental data for $\mathrm{Ni}_{44} \mathrm{Fe}_{6} \mathrm{Mn}_{32} \mathrm{Al}_{18}$ and $\mathrm{Fe}_{43.5} \mathrm{Ni}_{7.5} \mathrm{Mn}_{34} \mathrm{Al}_{15}$ alloys [9-11].

In Fig. 7 we show calculation results of theoretical Curie temperature of austenite for $\mathrm{Fe}_{x} \mathrm{Ni}_{2-x} \mathrm{Mn}_{1+y} \mathrm{Al}_{1-y}$ $(0.2 \leq x \leq 1.8 ; 0.0 \leq y \leq 0.6)$ compositions as a function of $\mathrm{Fe}$ content. These data were taken from thermomagnetization curves simulated by Monte Carlo technique. Our calculations have shown that for compositions containing the Mn excess $(y>0)$ the Curie temperatures firstly increase and further decrease with increasing $\mathrm{Fe}$ excess $(x)$. But for compositions with $y=0$ it is found to decrease with increase of $x$ content. The largest value of $T_{C}(\approx 455 \mathrm{~K})$ is observed for composition with $x=1.4$ and $y=0.6$.

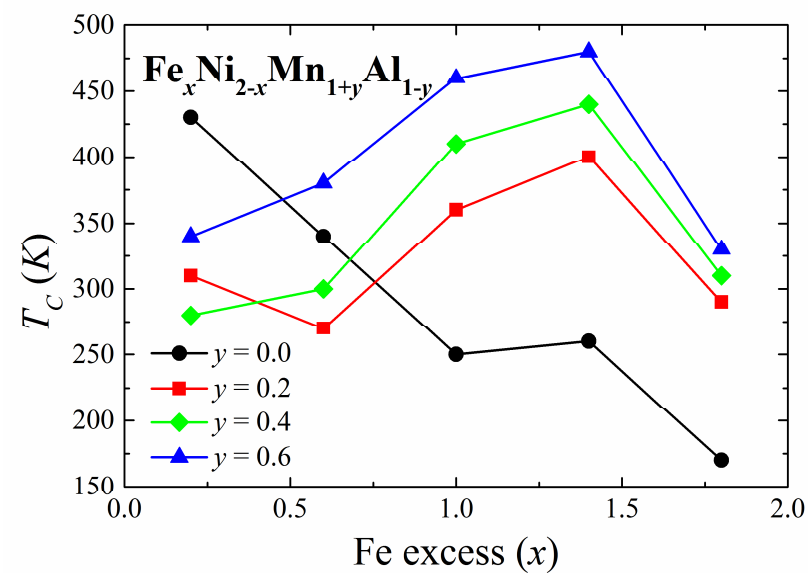

Figure 7. Calculated Curie temperature in austenite of $\mathrm{Fe}_{x} \mathrm{Ni}_{2-x} \mathrm{Mn}_{1+y} \mathrm{Al}_{1-y}$ for different value of Mn excess $(y)$ as a function of $\mathrm{Fe}$ excess $(x)$.

The main obtained results are listed in Table 1.

\section{Summary}

The composition dependence of crystal lattice parameters, bulk moduli, magnetic moments, magnetic exchange parameters, and Curie temperatures of austenite in $\mathrm{Fe}_{x} \mathrm{Ni}_{2-x} \mathrm{Mn}_{1+y} \mathrm{Al}_{1-y}(0.2 \leq x \leq 1.8 ; 0.0 \leq y \leq 0.6)$ Heusler alloys have been calculated using a combination of first principles and Monte Carlo approaches. The equilibrium lattice parameters were found to increase with increasing Fe content $(x)$. The strong competitive behavior between $\mathrm{FM}$ and $\mathrm{AF}$ interactions is the reason of a complex magnetic structure. An increase of $\mathrm{Fe}$ content results in an increase of exchange magnetic interactions between $\mathrm{Mn}$ atoms at regular positions and $\mathrm{Mn}$ atoms located at Al positions. The crossover from AF to $\mathrm{FM}$ interaction was found for compositions with $y=1.4$. Calculated values of lattice parameters and magnetic moments are in a good agreement with theoretical and experimental data [21]. It should be noted that for more complete understanding of crystal and magnetic structure it is necessary to investigate different magnetic structures. 
Table 1. Calculated equilibrium lattice constant $a$, bulk modulus $B$, spin magnetic moment $m$ and Curie temperature of austenite $T_{C}^{A}$, of $\mathrm{Fe}_{x} \mathrm{Ni}_{2-x} \mathrm{Mn}_{1+y} \mathrm{Al}_{1-y}$ alloys.

\begin{tabular}{|c|c|c|c|c|}
\hline $\mathrm{Composition}$ & $a, \AA$ & $B, \mathrm{GPa}$ & $m, \mu \mathrm{B}$ & $T_{C}{ }^{A}, \mathrm{~K}$ \\
\hline $\mathrm{Fe}_{0.2} \mathrm{Ni}_{1.8} \mathrm{Mn}_{1.0} \mathrm{Al}_{1.0}$ & 5.83 & 155.8 & 4.13 & 430 \\
\hline $\mathrm{Fe}_{0.6} \mathrm{Ni}_{1.4} \mathrm{Mn}_{1.0} \mathrm{Al}_{1.0}$ & 5.81 & 148.5 & 4.23 & 340 \\
\hline $\mathrm{Fe}_{1.0} \mathrm{Ni}_{1.0} \mathrm{Mn}_{1.0} \mathrm{Al}_{1.0}$ & 5.81 & 134.5 & 4.68 & 250 \\
\hline $\mathrm{Fe}_{1.4} \mathrm{Ni}_{0.6} \mathrm{Mn}_{1.0} \mathrm{Al}_{1.0}$ & 5.80 & 128.2 & 5.02 & 260 \\
\hline $\mathrm{Fe}_{1.8} \mathrm{Ni}_{0.2} \mathrm{Mn}_{1.0} \mathrm{Al}_{1.0}$ & 5.79 & 158.4 & 5.31 & 170 \\
\hline $\mathrm{Fe}_{0.2} \mathrm{Ni}_{1.8} \mathrm{Mn}_{1.2} \mathrm{Al}_{0.8}$ & 5.83 & 188.3 & 5.01 & 310 \\
\hline $\mathrm{Fe}_{0.6} \mathrm{Ni}_{1.4} \mathrm{Mn}_{1.2} \mathrm{Al}_{0.8}$ & 5.82 & 146.8 & 5.16 & 270 \\
\hline $\mathrm{Fe}_{1.0} \mathrm{Ni}_{1.0} \mathrm{Mn}_{1.2} \mathrm{Al}_{0.8}$ & 5.81 & 151.8 & 5.55 & 360 \\
\hline $\mathrm{Fe}_{1.4} \mathrm{Ni}_{0.6} \mathrm{Mn}_{1.2} \mathrm{Al}_{0.8}$ & 5.79 & 128.3 & 5.66 & 400 \\
\hline $\mathrm{Fe}_{1.8} \mathrm{Ni}_{0.2} \mathrm{Mn}_{1.2} \mathrm{Al}_{0.8}$ & 5.79 & 140.3 & 5.79 & 290 \\
\hline $\mathrm{Fe}_{0.2} \mathrm{Ni}_{1.8} \mathrm{Mn}_{1.4} \mathrm{Al}_{0.6}$ & 5.84 & 204.1 & 5.95 & 280 \\
\hline $\mathrm{Fe}_{0.6} \mathrm{Ni}_{1.4} \mathrm{Mn}_{1.4} \mathrm{Al}_{0.6}$ & 5.83 & 145.6 & 6.13 & 300 \\
\hline $\mathrm{Fe}_{1.0} \mathrm{Ni}_{1.0} \mathrm{Mn}_{1.4} \mathrm{Al}_{0.6}$ & 5.82 & 124.3 & 6.35 & 410 \\
\hline $\mathrm{Fe}_{1.4} \mathrm{Ni}_{0.6} \mathrm{Mn}_{1.4} \mathrm{Al}_{0.6}$ & 5.78 & 117.3 & 6.29 & 440 \\
\hline $\mathrm{Fe}_{1.8} \mathrm{Ni}_{0.2} \mathrm{Mn}_{1.4} \mathrm{Al}_{0.6}$ & 5.78 & 147.1 & 6.11 & 310 \\
\hline $\mathrm{Fe}_{0.2} \mathrm{Ni}_{1.8} \mathrm{Mn}_{1.6} \mathrm{Ni}_{0.0} \mathrm{Mn}_{0.4} \mathrm{Mn}_{1.6} \mathrm{Al}_{0.4}$ & 5.88 & 85.2 & 6.94 & 340 \\
\hline $\mathrm{Fe}_{0.6} \mathrm{Ni}_{1.4} \mathrm{Mn}_{1.6} \mathrm{Al}_{0.4}$ & 5.84 & 143.1 & 7.11 & 380 \\
\hline $\mathrm{Fi}_{1.6} \mathrm{Al}_{0.4}$ & 5.81 & 109.1 & 7.07 & 460 \\
\hline
\end{tabular}

\section{Acknowledgments}

This work was supported by Russian Science Fund No. 14-12-00570 (Section 1), Ministry of Education and Science RF No. 3.2021.2014/K (Section 4), RFBR (grants 14-02-01085, 14-02-31189).

\section{References}

1. V.D. Buchel'nikov, A.N. Vasiliev, V.V. Koledov, S.V. Taskaev, V.V. Khovailo, and V.G. Shavrov. Phys. Usp. 49, 871 (2006).

2. P. Entel, M.E. Gruner, A. Dannenberg, M. Siewert, S.K. Nayak, H.C. Herper, and V. Buchelnikov. Mater. Sci. Forum 635, 3 (2010).
3. G.A. Perez Alcazar, L.E. Zamora, and A. Bohorquez. J. Appl. Phys. 79, 6155 (1996).

4. S.M. Azar, B.A. Hamad, and J.M. Khalifeh. J. Magn. Magn. Mater. 324, 1776 (2012).

5. V.D. Buchelnikov, M.A. Zagrebin, V.V. Sokolovskiy, I.A. Taranenko, and A. T. Zayak. Phys. Status Solidi C 11, 979 (2014).

6. R. Umino, X.J. Liu, Y. Sutou, C.P. Wang, I. Ohnuma, R. Kainuma, and K. Ishida. J. Phase Equilib. Diff. 27, 54 (2006).

7. Y. Liao and I. Baker. Mater. Charact. 59, 1546 (2008).

8. I. Baker, X. Wu, F. Meng, and P.R. Munroe. Mater. Sci. Forum 783, 786 (2014).

9. T. Omori, K. Ando, M. Okano, X. Xu, Y. Tanaka, I. Ohnuma, R. Kainuma, and K. Ishida. Science, 333, 68 (2011).

10. T. Omori, M. Okano, and R. Kainuma. APL Materials 1, 032103 (2013).

11. L.W. Tseng, Ji. Ma, S.J.Wang, I. Karaman, M. Kaya, Z.P. Luod, and Y.I. Chumlyakov. Acta Mater. 89, 374 (2015).

12. H.C. Xuan, Y.Q. Zhang, H. Li, P.D. Han, D.H. Wang, and Y. W. Du. Appl. Phys. A.-Mater. 119, 597 (2015).

13. H. Ebert. SPRKKR package (version 6.3). http://ebert.cup.uni-muenchen.de/.

14. .H. Ebert, D. Kodderitzsch, and J. Minar. Rep. Prog. Phys., 74, 096501 (2011).

15. A.I. Liechtenstein, M.I. Katsnelson, V.P. Antropov, and V.A. Gubanov. J. Magn. Magn. Mater. 67, 65 (1987).

16. J.P. Perdew, K. Burke, and M. Ernzerhof. Phys. Rev. B. 77, 3865 (1997).

17. V.V. Sokolovskiy, O. Pavlukhina, V.D. Buchelnikov and P. Entel. J. Phys. D: Appl. Phys. 47, 425002 (2014).

18. V.D. Buchelnikov, V.V. Sokolovskiy, H.C. Herper, H. Ebert, M.E. Gruner, S.V. Taskaev, V.V. Khovaylo, A. Hucht, A. Dannenberg, M. Ogura, H. Akai, M. Acet, and P. Entel. Phys. Rev. B, 81, 094411 (2010).

19. T. Busgen, J. Feydt, R. Hassdorf, S. Thienhaus, M. Moske, M. Boese, A. Zayak, and P. Entel. Phys. Rev. B, 70, 014111 (2004).

20. C. Kittel. Introduction to Solid State Physics (Wiley \& Sons Inc, 2005).

21. V.D. Buchelnikov, M.A. Klyuchnikova, M.A. Zagrebin, and V.V. Sokolovskiy. Sol. State Phenom. 233-234, 187 (2015). 
